\title{
A paradox in the supervision of doctoral candidates in Ugandan higher education institutions (HEIs)
}

\author{
Maria Kaguhangire-Barifaijo* and James L. Nkata \\ Uganda Management Institute, Uganda.
}

Received 21 July, 2021; Accepted 10 August, 2021

\begin{abstract}
The paper examines the dynamics and complex dimensions in doctoral supervision in different disciplinary contexts in higher education institutions (HEls), given that institutional success and reputation depends on 'research output,' which creates visibility and competitive advantage. However, traditional doctoral supervision, which frequently results in research output, has remained contradictory and complex due to its multi-layered, challenging, and conflicting tasks. The authors contend that while doctoral supervision necessitates a high caliber pool of trained academics and professionals, with reasonable accommodation and respect for one another, strong ethical values, cordial relationships, and professionalism, institutions continue to face unprecedented challenges in not only finding all of the attributes in a single supervisor, but also finding the best supervision model to employ. The paper concludes that, because supervisors are appointed based on their methodological, experience, and content expertise, the other essential attributes for effective supervision should be incorporated into policies. As a result, in order to resolve supervision nuances, institutions should implement flawless doctoral supervision guidelines and provide healthy supervision environments.
\end{abstract}

Key words: Co-supervision, doctoral committees, doctoral supervision, doctoral education, team supervision, dyadic supervision.

\section{INTRODUCTION}

We begin by debating supervision fallacies: (1) that having a doctorate allows one to effectively supervise doctoral candidates; (2) that having two or more supervisors is better than single (dyadic) supervision; (3) that there is always collegial cooperation in cosupervision; (4) that everyone in team supervision will contribute maximally to the student's benefit, and (5) that the existing regulatory frameworks for doctoral programs have resolved dynamics in doctoral supervision. In fact, graduate or research supervision in general is a complex endeavor; however, doctoral supervision, which requires even greater intellectual capability, appears to be even more complex, with no single supervision model or style that can be exclusively applied and succeed (Lee and Murray, 2015).

Secondly, there has not been any evidence in the

${ }^{*}$ Corresponding author. E-mail: mbkaguhangire@umi.ac.ug.

Author(s) agree that this article remain permanently open access under the terms of the Creative Commons Attribution License 4.0 International License 
literature that a single approach is flawless. In general, different levels (e.g. undergraduate, masters and $\mathrm{PhD}$ ) exacerbate supervision, because the requirements for the different levels demand different supervision approaches, models, styles, competence, experience and rigor (Akerlind and McAlpine, 2017; Manathunga, 2011). As a result, while Armsby et al. (2017) and Angelito, 2014 advocate for rigorous supervisor training and mentoring to resolve supervision dynamics, training alone may not provide all of the answers for failed supervision, because many supervisors resent the minutiae that surround research supervision (Bitzer and Albertyn, 2011; Massyn, 2018). In fact, most supervisors lack the patience to deal with students' 'mess', particularly at Masters level, where it is about 'correcting grammar', 'typos', 'punctuations', 'paragraphing', 'writing structure,' etc (Armsby et al., 2017). Nonetheless, some supervisors flip through the pages, but without paying close attention to the minutiae details (Bitzer and Albertyn, 2011). In fact, while some supervisors successfully deal with the uncertainty of the Masters' research projects, it is unlikely that a doctoral supervisor will be able to do so (Armsby et al., 2017). As a result, Hutchings (2017) recommends that institutions develop clear, well-articulated standards and guidelines for all supervision decisions that may jeopardize institutional quality and profiling, as well as graduate student attraction.

\section{The context and problem}

There are stories of research students grumbling and complaining about strange and mean professors with odd habits and full of eccentricity in every corridor, walkway, and cafeteria - around campuses, while others are stuck in the battle field of the supervisors (Manathunga, 2014). Despite the fact that this occurs on a daily basis, graduate schools continue to receive complaints from supervisees about their irritable supervisors (Barifaijo et al., 2010). Unlike previous discussions which focused on memories of strange misunderstandings between $\mathrm{PhD}$ students and their supervisors (Lee and Murray, 2015), the current discussion focused on models of doctoral supervision. While all supervision models have detractors, co-supervision dynamics have become a nightmare, as students always lament along university hallways about the fights of the two supervisors for "failure to agree on a simple research aspect" (Lahenius and Ikãvalko, 2012), or sometimes about the issue of neglect in case of a single supervisor (Fell et al., 2011). However, universities have been perplexed when not only the two supervisors conflict, but also divergent views of doctoral committee members or disagreements between supervisor and supervisee (Chiappetta-Swanson and Watt, 2011). While supervision disagreements arise from a variety of factors, including knowledge and skills of supervisors, writing style, and availability of the students, the use of 'First and Second' supervisors, which has been perceived as merely 'cosmetic,' continues to be detrimental in academia (Fell et al., 2011). For this reason, quality of doctoral supervision remains wanting (Malunda et al., 2021).

Nonetheless, while literature has focused on supervisor disagreements - whether co-supervision, dyadic or team supervision - personality clashes continue to make supervision processes extremely complex, yet difficult to rectify due to the nature of its hidden censures (Hawkins and Shohet, 2012). Traditionally, decisions for doctoral supervision appointments were influenced by the following factors: area of specialization, expertise, experience, and reputation (Lahenius and Ikãvalko, 2012). Doctoral committees or group supervision, joint supervision, co-supervision, and single supervision are some of the models used in Uganda for doctoral supervision (Katunguka, 2007). However, due to limited capacity of supervisors, universities have devised strategies such as paring senior and novice academics, paring two professors from different disciplines, pairing an external and internal professor, as well as partnerships that have become an avenue for doctoral supervision. Whereas the aforementioned strategies were intended to address supervision issues, new dynamics emerged, exacerbating the already strained supervision relationships (IRIC, 2017 Quarterly Report). There have been dysfunctional conflicts that have resulted in supervisor disengagement; while some students were deregistered for overstaying on the programs, others spent double the recommended time for doctoral completion, and still others became frustrated and withdrew from doctoral programs entirely. This situation could jeopardize institutional image, visibility, profiling, and competitiveness. To resolve this paradox, three goals were established: (1) to examine preferred doctoral supervision models, (2) to establish the basis for supervisory allocation decisions, and (3) to analyze the implications of persistent challenges in doctoral supervision.

\section{THEORETICAL EXPLORATION AND LITERATURE REVIEW}

Bandura's theory of reciprocal determinism was used to explain the environment in which supervisors work, including supervision policies, institutional structures, and funding policies. According to the theory, a person's behavior influences and is influenced by either his or her personal and social environment (Akoul, 1998). Similarly, an individual's behavior can be conditioned through the use of consequences, which can impact or be impacted by the environment at the same time (Laceulle, 2015). As a result, behavior is controlled or determined by both the 
individual, via cognitive processes, and the environment, via external social stimulus events. When compared to cognitive, environmental, and external social stimulus events, reciprocal determinism should assist individuals in transforming themselves to allow subjective thought transparency (Jeronimus, 2014; Laceulle, 2015). As a result, much like how supervisors' behavior is influenced by the environment in which they work - such as culture, values, status, compensation, and overall treatment these factors interact with the personalities of those individuals; it becomes the reciprocal associations between individual behavior/personality and their environments because individual actions cannot go one way since they are affected by repercussions and complications. These skill sets result in an under- or overcompensated ego that is either too strong or too weak to focus on pure outcome for all creative purposes. According to Jeronimus (2014), reciprocal determinism is the idea that behavior is controlled or determined by both the individual (via cognitive processes) and the environment (via external social stimulus events). When compared to cognitive, environmental, and external social stimulus events, the basis of reciprocal determinism should transform individual behavior by allowing subjective thought to processes transparency. As a result, actions do not go in one direction or the other because they are affected by repercussions, implying that one's behavior is complicated and cannot be thought of as individual and environmental means. Consequently, behavior which is made up of environmental and individual components should work together to function.

\section{Conceptual orientation}

With the increasing demand for doctoral education, doctoral supervision became common practice and significant due to the complexity involved, especially with the inevitability of personal, academic, ethical, and sometimes cross-cultural issues of individuals. The term co-supervision, as the name implies, refers to the formal agreement of two or more academics in doctoral programs to supervise a research student (Abiddin et al., 2011; Hutchings, 2017; McCulloch et al., 2016). Thesis supervisors and their students have a well-defined interpersonal relationship, which is referred to as supervision. Co-supervision, by implication, entails two academics sharing the entire responsibility of guiding a doctoral student from the time the candidate develops a concept, through proposal generation, and finally to thesis writing (Spooner-Lane et al., 2007). Cosupervision, in its ideal form, promotes the clarification of clear expectations and opens the door to mentorship and professional development in a realigned supervisory relationship. Given the anticipated benefits, most higher education institutions (HEIs) have adopted the model.
Paradoxically, despite the numerous benefits, cosupervision has made the supervision process sufficiently difficult due to the additional communication issues that involve more than two people (Hutchings, 2017). Team supervision, on the other hand, is used to describe shared supervisory arrangements that all potentially pause challenges due to inevitable conflicts caused by human interaction (Robertson, 2017a, b; Guerin, 2018; Watts, 2010). Similarly, single or dyadic supervision occurs when a single individual takes on a doctoral candidate from idea inception to concept exploration, proposal development, research and dissertation writing, and submission. As a result, whether in co-supervision, single supervision, or team supervision, there are inherent challenges to be addressed, given that a doctoral program, unlike other qualifications, is a "deal breaker," a distinguisher, an increase in leverage, and a class stratifier. By implication, the rigor, quality and purpose are paramount.

Scholars (Armsby et al., 2017; McAlpine, 2013; Lizzio et al., 2005) articulate the distinctiveness of doctoral programs, doctoral candidates and doctoral degrees. According to McCulloch and Loeser (2016), a Doctor of Philosophy (PhD, Ph.D., or DPhil) is the highest university degree and is awarded for programs spanning the entire breadth of academic fields and with varying models such as a PhD by Research only, a PhD by Coursework and extended essay, a PhD by publication, and a PhD by Research and Coursework (Taylor, 2017). Accordingly, 'a doctoral or PhD student' is defined as someone who is still pursuing the coursework portion of the program and becomes a doctoral or $\mathrm{PhD}$ candidate when she/he begins writing the thesis/dissertation. Surprisingly, the literature has been deafeningly silent on the other three types of doctoral programs: a PhD by research, a PhD by coursework only, and a PhD by publication. Notably, university-awarded doctorates have proliferated around the world, and while a doctorate usually entitles one to be addressed as "doctor," the use of the title varies greatly depending on the type and associated occupation (Kiley, 2011; Guerin et al., 2015a; Fenge, 2012). Other types of doctorates include "Research Doctorates", "Licentiate", "Higher doctorate and post-doctoral degrees", "Professional Doctorate", and "Honorary Doctorate" (Fillery-Travis et al., 2017; Armsby et al., 2017). While some of these doctorates necessitate strict supervision, others are more lenient, while others may only necessitate minimal supervision. Still others are merely ceremonial awards. Notably, the paper specifically addresses academic doctorates that necessitate the supervision of two or more experts, which frequently results in total chaos.

Similarly, Fillery-Travis et al. (2017) advanced two models of supervision: (1) the social science and (2) the natural sciences model. Within these two models. There are various models and approaches embedded within 
these two models, each with its own set of benefits and drawbacks. There is team supervision and co-supervision in these models. Turner (2015) defines supervision models based on modes, purpose, and arrangement. He affirms that although most scholars (Bitzer and Albertyn, 2011; Fell et al., 2011; Calma, 2011) identified gaps in co-supervision, he actually found unmatched benefits in co-supervision, such as greater expertise with multiple supervisory input, a second opinion from someone who is familiar with the research, less likelihood of dependence on one particular person, and insurance against supervisor mobility. Contrary to previous scholars, Lahenius and Ikvalk (2012) argue that co-supervision can never succeed unless the two supervisors have strong collegial cooperation with a well-developed collaboration, open communication, and trust, have taught or published together, conducted joint research, or participated in a task together. Similarly, Wisker and Robinson (2013) and McCulloch et al. (2016) argue that the success of supervision may be determined by factors other than the supervision model used, such as personality, environment, culture etc. They explain how each supervisor and candidate differ significantly, and how these differences result in supervision idiosyncrasies. Inter-supervisory expectations, variations in departmental norms, the structure of a thesis, interpretation of supervisory tasks, and feedback time may all contribute to supervision inconsistencies (Fillery-Travis et al., 2017; Orellana, 2016).

Wadesango and Machingambi (2011) discovered that co-supervisors worked in a variety of hierarchical structures, ranging from distinctly pyramidal arrangements in which the 'principal' or 'primary' or 'first' supervisor is the senior supervisor - often with the final say on any research project decisions. Unfortunately, the terms "first" and "second" supervisors have caused significant confusion. However, Hammond et al. (2010) explain how these terms were simply nomenclatural expressions and did not necessarily denote 'superior' or 'inferior' to the other. Contrary to the 'First', 'Senior', 'Primary' or 'Principal' supervisors, the 'junior', "novice" or 'Second' supervisors possessed superior commitment, time, and content knowledge, and also had more regular day-today contact with the students (Hawkins and Shohet, 2012). In fact, the novice supervisors felt unappreciated for putting in all the effort and receiving far less than their fair share of the credit - especially when the student completes successfully and in record time (McCulloch and Loeser, 2016). Ironically, although Armsby, et al. (2017) advocate for co-supervision because the second supervisor lessens the pressure and stress, McCulloch and Loeser (2016) found that the majority of professors prefer to engage in solo supervision all through, and in cases where a second supervisor is imposed on them, they only access the draft thesis towards the end of candidature. This is very frustrating to the candidate, especially when the second reader identifies serious content, methodology or even structural issues when the thesis is almost ready for submission. Indeed, studies by Lee (2012) and McCallin and Nayar (2012) show that, despite dependence and reliability issues with single supervision, students often progressed smoothly - with a cordial relationship with their one supervisor. Manathunga (2012) discovered that the majority of doctoral supervisors preferred to guide the student solely - from conceptualization to the end of the research project - in order to reduce the confusion caused by divergent views and feedback from the two supervisors. Consequently, Lizzio et al. (2005) agree that a single supervision model for doctoral candidates has numerous benefits.

On the other hand, four (4) models of supervision are revealed, namely: (1) the functional model (2) the relationship development model (3) the emancipation model and (4) the critical thinking model (Akerlind and McAlpine, 2017; Fenge, 2012; Guerin and Green, 2015b). In the 'Functional Model', supervisors play the role of the director, guiding students with an emphasis on skill acquisition and development, as well as the completion of various degree requirements. The 'Relationship Development Model', on the other hand, emphasizes the supervisor's need for emotional intelligence in order to deal with a variety of studentsrelated challenges. The 'Emancipation Model' emphasizes the role of supervisors as mentors, guiding students toward independence. Nonetheless in the 'Critical Thinking Model', supervisors actively develop their students' critical thinking and analytical skills by evaluating and challenging them and their ideas. According to this model, the most effective supervisors should use a combination of these styles depending on the needs of their students. Nonetheless, Carter (2016) proposed the social science model and the natural sciences model, both of which are concerned with the relationship in the supervision process. Unlike the latter models, which refer to the desired relationship for effective supervision, Akerlind and McAlpine (2017) models propose essential supervision practices. In contrast to the first three supervision models, which explain supervision arrangements, the latter two are more about best practices in terms of competences, professionalism, and acceptable behaviour expected of a supervisor - regardless of whether dyadic, dual, or team arrangements.

Given the inherent challenges of solo and cosupervision, Guerin (2018) strongly recommends team supervision or doctoral committees because it is more difficult for the candidate to fall victim to the squabbles of the two or be dominated by one supervisor. As a result, Hutchings (2017) prefers doctoral committees to pool content, experience, and methodological expertise in team supervision because they boost quality, improve 
timely completion, and assist in covering absences of other members - in the event that members are away on sabbatical, study, maternity, compassionate, or even sick leave. Sometimes the absence is of a specific nature, such as during busy periods of teaching or administrative responsibilities (Hutchings, 2017). Other benefits of doctoral committees are its potential to obviate abandonment of a student in case of single supervision model - leading to 'doctoral orphans', greater expertise (two heads are better than one since team or doctoral supervision inhibits the risk of supervisory incompetence and increased completion chances), a second opinion (always having a team of experts who offer valuable opinions and making brilliant contributions), avoiding dependency (the team builds confidence and the candidate is less likely to become dependent on one individual to direct their work), and insurance (provide the opportunity for novice supervisors and early career researchers to learn how things are done from experienced colleagues on the team) (Manathunga, 2011; Wisker and Robinson, 2013). Furthermore, through team supervision academics adjust and learn to work well together - each one bringing excellent perspectives - and the doctoral student learns that there are multiple points of views and that academic discourse promotes the development of research rigor (Fell et al., 2011). As a result, with the help of a team of supervisors, the story of 'abandoned' or 'orphaned' doctoral students becomes history.

Nonetheless, in a twisted event, team supervision poses a risk of free riders on the team who wait to append their signatures in order to target tenure, promotion, or other opportunities such as financial incentives (Zhao et al., 2007). As a result, given the sophistication of team supervision, there should be an accountability mechanism in place to ensure that every team member contributes meaningfully (Chris et al., 2007). Finally, universities make the dangerous assumption that only those with doctorates can supervise. Those who have emerged from their own doctoral trainings - and straight into academic environments to supervise - may not have much to contribute, as the adage goes, "taking a fish out of water and putting it on dry land and expecting it to move." This assumption has caused more confusion among students and disagreements among supervisors, as novice supervisors frequently demonstrate their intellectual curiosity in order to apply new skills - right from the university (Hutchings, 2017).

\section{METHODOLOGY}

The paper was based on interpretivism, ethnographic inquiry and integrative synthesis which were believed to be the most appropriate methods for this discussion. Scholars such as Kothari (2006), Creswell (2012), and Gall et al. (1996) recommend this combination for summarizing literature and observing human behavior in a natural setting. Archival data, review summaries, and observations on trends in doctoral supervision were adopted. Purposively selected academics and institutional heads from the two institutions (Makerere University and Uganda Management Institute) were interviewed using a semi-structured instrument (Kothari, 2013), regarding supervision models used, nature of challenges encountered and benchmarks in supervision allocation. Using content, thematic, and narrative techniques, relevant policies, doctoral supervision guidelines, progress reports, and research directorate minutes were analyzed. Creswell (2012) supported the use of the same measurement on the challenges of doctoral supervision to collect data. To determine the impact of cosupervision in the two institutions, thematic analysis was used to organize themes in the specific mandates of higher education. Because they were both government-funded and research-based institutions with doctoral programs, hence, a valid comparison in institutions was possible.

\section{FINDINGS AND DISCUSSION}

Graduate or research supervision is a complex endeavor that does not have a single model or style that can be used exclusively. It is exacerbated further by the fact that different levels (undergraduate, masters, and $\mathrm{PhD}$ ) necessitate different approaches, models, and styles of supervision - depending on the rigor required (Akerlind and McAlpine, 2017; Cousin, 2009; Fenge, 2012; Guerin and Green, 2015b). According to Akerlind and McAlpine (2017), there were three (3) major models of doctoral supervision, namely; (1) co-supervision and (2) doctoral committees, and (3) single/solo or dyadic model of supervision. The model of dyadic or single supervision was justified because of the nature of the doctoral candidates - who were mature, well-prepared, highly motivated, and already holding senior positions. The second justification is where there was scarcity of experts in certain fields such as Public Procurement, Economics, Statistics, Commerce etc. The third justification was that the supervisors in this supervision model were accomplished scholars who were very well grounded in their disciplines. We further established that although the National Council for Higher Education (NCHE) was clear on promotional requirements, some Associate Professors with no doctorates had attained the ranks before the 'Mujaju Report' so, even as Associate Professors, they were not eligible to supervise doctoral candidates. In the two institutions therefore, co-supervision was the most preferred model, given its benefits for both supervisors and students. Similarly, Feng Lee-Ann (2012) found that some aspects of good supervision were universal and that some supervision styles varied across countries, institutions, and disciplines, allowing supervisors from different countries and institutions to be paired.

Similar to the 'peer supervision' model, in the research group or laboratory-based model traditionally used in the "hard" disciplines, we found that in natural science and medicine, research fellows and graduate students worked together to support each other in the process," with the supervisor serving as the group's moderator. This 
approach fosters a sense of community and has the potential to foster a lively, casual, and collegial environment, and students reported numerous benefits as a result of the connectedness, free, and conducive environment that draws them to shared research goals (Katunguka, 2007). Hence, this new model of supervision was a hybrid given that students have the opportunity to work with their peers as well as report to a group of professors, which greatly reduced the isolation caused by the traditional approach as well as "diffusing power and increasing social learning in collaborative and collective environments". Like Bitzer and Albertyn (2011), we discovered that effective use of 'peer supervision' reduced dependence on supervisors and increased the students' sense of self; creates a sense of a community of researchers, and assists novice researchers in establishing their research identity while simultaneously focusing on skill development; assisted students in producing higher quality dissertations; assisted students in gaining insights during contributions and interaction, which encourages students to think behind actions (Bitzer and Albertyn, 2011). Nonetheless, we discovered that peer supervision or group approaches required structure, guidance, and modelling of constructive behavior in order to reduce shy students' fear of participation and to quell the domineering personalities of more forceful students. In fact, this approach of supervision necessitates effective leadership in order to prevent an inexperienced group from "pooling ignorance" (McCallin and Nayar, 2012).

Similarly, the traditional model was preferred because it provided adequate amounts of encouragement, advice, support, constructive and critical appraisal, and encouragement to develop independent and analytical thinking in terms of problem solving. This model was also found to be flexible, supervisee-centered, and reflective, with the supervisor and supervisee sharing mutual control of the learning process. Yet, Carter (2016) discovered that the facilitative approach reduced students' confusion and anxiety, which positively influenced student perceptions of supervisor capability and effectiveness. Nevertheless, for co-supervision to be effective, students and supervisors must regularly meet to discuss and agree on their needs early in the relationship - their expectations, responsibilities, and ways of working together (Akerlind and McAlpine, 2017). They recommend holding meetings at regular intervals, with agreed-upon plans of action and detailed written records of everything done so far. They also advise supervisors to be open to new approaches to the subject as well as new perspectives on methods. Similarly, because the student has opinions and understanding of the research issues, the two supervisors should give him or her an opportunity to express them. Gill and Bernard (2008) discovered that, because supervision is typically a private activity, 'principles of practice' are frequently learned through personal experience, recognizing the practice of others, and institutional requirements for procedural alignment.

According to Barifaijo and Nkata (2018), co-supervision benefits novice supervisors by exposing them to the expertise of the principal supervisor. Many of the traditional methods of research supervision have been disrupted as a result of changes in supervision arrangements. For example, a dyadic model was popular when there were few well-prepared doctoral students who were supervised over an extended period of time by committed and motivated professors (Manathunga, 2012). The supervision arrangement was straightforward, given that supervisors not only lived on-campus, but were also full-time university employees who prepared students for academic or other full-time research work. Similarly, students were campus residents who had easy access to facilities such as libraries, free secretarial services, or at the very least university computers (Hawkins and Shohet, 2012). Today, a dyadic model cannot accommodate changing students' needs and expectations while also addressing the stringent financial situation of universities. Indeed, group supervision was found to be aversive, and students were prevented from benefiting from such experience due to excessive bureaucracy, particularly on issues of first or second supervisor (Fleming and Steen, 2012). Teams were also found to be anxiety-inducing, with some members feeling less safe than if they were in a one-on-one supervision setting (Fleming and Steen, 2012). Because of the pressure to conform to group norms, such group dynamics had made group supervision even more difficult (Hawkins and Shohet, 2012). Even senior professors admitted that supervising a group was difficult and emotionally draining, but also highly rewarding and energizing.

Joint or co-supervision supervisory arrangements were found to be more prevalent than the single supervisor model in the social sciences, particularly at the doctoral level. However, one supervisor model predominated in private universities, possibly due to the costs involved. In support of this finding, Gill and Bernard (2008) discovered that where joint supervision existed within the social sciences, there were two supervisors as well as doctoral committees. We also discovered joint supervision in institutional or action research, particularly in medicine, sociology, and natural sciences. Other reasons for collaborating researchers included the nature of the research due to synergy and the need for specialized knowledge. As a result, the 'primary' or 'principal' or 'senior' supervisor was ultimately responsible for guiding researchers. We also discovered that the primary supervisor had the final say on the academic work of the students. This finding was supported by Gill and Bernard (2008) and Golde and Walker (2006) in the natural sciences model, where a designated 'senior' supervisor did not play a lead or central role in the 
supervision of the student' (Guerin et al., 2011). A new supervision model or arrangement of 'peer supervision' was found in one of the institutions, as long as the team of students was well-prepared, self-driven, and possessed exceptional intellectual capacity. Although there is some anecdotal evidence of peer supervision in the literature, we found it to be very unique and important because it promoted knowledge sharing among students and between supervisors. Unlike traditional models of supervision, which involved a 'supervisor' or 'teams of supervisors', peer supervision comprised only doctoral students organized according to thematic areas - where all the students in the team were in sync. In this model, students gave each other advice, shared information, but also accessed institutional resources in a group setting. Students organized workshops and seminars in the form of methodology groups and collaborative cohorts with the help of institutions (Egan et al., 2009). As a result of these fundamental changes in supervision models, a knowledge management approach to research supervision is required.

Seniority (e.g., senior lecturer - full professor), discipline/specialization, and experience were the three main reasons for doctoral supervision allocation decisions. The first two are self-explanatory, whereas the third does not necessarily depend on the number of years spent supervising, but rather on tested ability on other tasks. Such considerations were made due to a lack of limited promotional openings in specific schools or departments, despite the fact that these individuals met all of the requirements for supervision. Similarly, internationalization has altered methods of supervision, particularly where students were registered in two institutions and taking courses in both. It was previously required for each institution to provide a supervisor (international/external supervisors). Hence decisions of most supervision allocation were driven by its value in determining career growth of faculty, 'advocacy for mentorship' as well as 'equitability' through workload rationalization that put pressure for staff to produce outputs - faster and in greater numbers. This aspect further exacerbated supervision rationalization, which led some staff to supervise areas where they had no competences, but also interest (Barifaijo and Namara, 2016; van Rooij et al., 2019). Although this was mostly for supervision of masters' students, there were cases for doctoral students where some supervisors had no experience, never published - but had PhDs, while others with professional doctorates engaged in supervising $\mathrm{PhD}$ students. Cousin (2009) confirmed this finding, but advised institutions to be mindful not only of quality, but also of the 'superior-inferior' relational dynamics. In addition, to fill gaps caused by a lack of adequate supervision capacity, institutions implemented 'crossinstitutional' supervision.

Without disparaging co-supervision, there were numerous complex, multifaceted, and dynamic human interactions as a result of their unpredictability. Such hiccups harmed not only the quality of supervisorsupervisor interaction, but the supervision as well as institutional image. Carrigan discovered that supervising graduate students was a complex form of pedagogy as well Guerine and Green (2015a). They argued that the changing nature of higher education institutions management, the increasing diversity of our students, the cross-disciplinary nature of academic research, and the desire to develop new knowledge - made it even more complicated. Nonetheless, despite its popularity, cosupervision had a negative impact on collegiality and free participation, particularly with the imagined hierarchy of 'the first' and 'the second' supervisors. Carrigan (2016) concluded that institutional supervision protocols had built walls rather than bridges that unite and connect colleagues. Similarly, within this hierarchical model, there was unarticulated expectation that the second supervisor was less important than the first, which Guerin and Green (2015b) disputed.

Supervision models aside, other issues arose as a result of the various types of PhDs, such as doctor of practice or practice-based, doctor by publication and sometimes doctor by coursework. In fact, according to Guerine and Green (2015a), some of these doctors lacked the philosophical perspective or intellectual authority to supervise 'doctoral students of philosophy'. Other personality-related challenges in co-supervision included toxicity, self-inflation, dominant characters, and free riders. Whereas senior supervisors required mentorship and interpersonal skills training, junior supervisors required more epistemological, ontological, and methodological deportment skills rather than facultycentric academic development workshops with often limited coverage. Cross-border or inter-institutional supervision had also created new dimensions to supervision, such as cross-cultural social integration which was frequently caused by different research orientations, varying levels of motivation, and, of course, the financial aspect (Savva and Nygaard, 2021), which we could not ignore. While some international supervisors withdrew their supervision support, others remained but withheld their decisions, and still others demanded to be paid directly by students (IRIC, 2017). Nonetheless, some professors had preferences for who they wanted to supervise with, whom they deemed to be "the perfect match." While some supervisors compared team supervision to therapeutic work, some supervisees were less likely than therapy clients to bring chronic concerns or urgent crises, so the sense of holding was often less charged. This preference further exacerbated the already existing conflicts. Nonetheless, despite the fact that group formation is frequently deceptive, the underlying interpersonal dynamics, needs, and sensitivities in supervisory relationships gradually emerge 
(Manathunga, 2012). This contrast between overt simplicity and covert complexity was especially noticeable in a supervision group, where the group session almost ran itself at times.

All the challenges notwithstanding, there were commensurable advantages in terms of take-home lessons and a well-functioning supervisory group.

\section{CONCLUSIONS AND RECOMMENDATIONS}

Given the spread of responsibility, there is "no gold standard model" for effective doctoral supervision. As a result, institutions should adopt models that are tailored to the student's methodological stance, supervisor specialization, type of doctorate, and student nature. Regardless of the challenges identified, co-supervision elicited greater confidence, assurance, security, quality, and synergy because it brings together exemplary researchers - far superior to a dyadic model. Second, in addition to the traditional doctoral supervisory benchmarks, other scales such as experience, previous performance, credibility, and ethical behavior were used to guide emergent decisions. However, the scarcity of qualified doctoral supervisors was exacerbated by the slow promotion of the most deserving academics. As a result, institutions must step up staff promotions, as the majority possessed the required intellectual quality to drive higher intellectual demands among doctoral candidates. Fortunately, with the emergent supervision decision, quality was never lost, given the existence of vibrant Quality Assurance Departments (QAD), which played a critical role. Lastly, no single supervisor is immune to supervision flaws, whether intellectual, commitment, personality, or otherwise. As a result, the emotional energies, which were frequently misunderstood, were an important part of team supervision and a resource - not wild animals to be tamed, controlled, or uprooted. As a result, the diverse viewpoints enrich intellectual interactions and scholarship. Diverse experiences, diffusion of responsibility, human interaction, and students who sometimes play one supervisor off the other contributed to the challenges. Institutions must therefore prioritize initial discussions or contracts between the supervisors and doctoral students to determine the goals and direction of supervision in order to build stronger and more effective relationships. Finally, institutions should work to eliminate miscommunication about the roles of the "first" and "second" supervisors, which has frequently resulted in fictitious hierarchies, prolonging student frustration and alienation.

\section{CONFLICT OF INTERESTS}

The authors have not declared any conflict of interest.

\section{REFERENCES}

Abiddin NZ, Ismail A, Ismail A (2011). Effective supervisory approach in enhancing postgraduate research studies. International Journal of Humanities and Social Science 1(2):206-217.

Akerlind G, McAlpine L (2017). Supervising Doctoral Students: Variation In Purpose and Pedagogy. Studies in Higher Education 42(9):16861698.

Akoul GM (1998). Perpetuating Passivity: Reliance and Reciprocal Determinism in Physician-Patient Interaction. Journal of Health Communication 3(3):233-259.

Angelito $C$ (2014). Challenges in preparing academic staff for research training and supervision: The case of the Philippines. International Journal of Educational Management 28(6):705-715.

Armsby P, Costley C, Cranfield S (2017). The Design of Doctorate Curricula for Practicing Professionals. Studies in Higher Education 43(12):2226-2237.

Barifaijo KM, Nkata JL (2018). ATINER's Conference Paper Series COLEDU2019-2650. Available at: http://www.atiner.gr/papers/COLEDU2019-2650.pdf

Barifaijo KM, Basheka BC, Oonyu J (2010). How to Write a Good Dissertation/Thesis? Available http://benonbasheka.com/publication/how-to-write-a-gooddissertation-thesis/

Barifaijo KM, Namara R (2016). Politics in Staff Representation and democracy in higher education institutions in Uganda: Extricating the actor's intentions. International Journal of Technology and Management 2(2):11-11.

Bitzer ME, Albertyn MR (2011). Alternative approaches to postgraduate supervision: A planning tool to facilitate supervisory processes. South African Journal of Higher Education 25(5):875-888.

Calma A (2011). Postgraduate research training: Some issues. Higher Education Quarterly 65(4):368-385.

Carrigan M (2016). Review - "Social Media for Academics". Available at: https://opietasanimi.com/2017/02/12/review-social-media-foracademics-mark- carrigan-2016/

Carter S (2016). Supervision learning as conceptual threshold crossing: when supervision gets 'medieval. Higher Education Research and Development 35(6):1139-1152

Chiappetta-Swanson C, Watt S (2011). Good practice in the supervision and mentoring of postgraduate students: It takes an academy to raise a scholar. USA: McMaster University.

Chris P, Andria H, Malgorzata K, Lee H (2007). Postgraduate Research Experience Survey - Final Report 2007. The Higher Education Academy, United Kingdom.

Cousin G (2009). Researching Learning in Higher Education. Abingdon: Routledge.

Creswell JW (2012). Qualitative inquiry \& research design: Choosing among five approaches (4thed.). Thousand Oaks, CA: Sage.

Egan R, Stockley D, Brouwer B, Tripp D, Stechyson N (2009). Relationships between area of academic concentration, supervisory style, student needs and best practices. Studies in Higher Education 34(3):337-345.

Fell A, Haines I, Flint K (2011). Professional Doctorates Report. Lichfield: UK Council for Graduate Education.

Fenge LA (2012). Enhancing the Doctoral Journey: The Role of Group Supervision in Supporting Collaborative Learning and Creativity. Studies in Higher Education 37(4):401-14.

Fillery-Travis A, Maguire K, Pizzolatti N, Robinson L, Lowley A, Stel N, Mans P (2017). Insights from Practice: A Handbook for Supervisors of Modern Doctorate Candidates. http://superprofdoc.eu/?page_id=71.

Fleming I, Steen L (2012). Supervision and clinical psychology: Theory, practice and perspectives, 2nd edition. Published by Routledge $P$ 280.

Gall MD, Borg WR, Gall JP (1996). Education research, an introduction. New York Longman Publishers.

Gill P, Bernard P (2008). The student-supervisor relationship in the $\mathrm{PhD} /$ doctoral process. British Journal of Nursing 17(1):668-671.

Golde C, Walker G (2006). Envisioning the Future of Doctoral 
Education: Preparing Stewards of the Discipline Carnegie Essays on the Doctorate. San Francisco, CA: Jossey-Bass.

Guerin C (2018). Co-supervision in Doctoral Education: Challenges and Responses. The University of Adelaide

Guerin C, Kerr H, Green I (2015a). Supervision pedagogies: Narratives from the field. Teaching in Higher Education 20(1):107-118.

Guerin C, Green I (2015b). They're the bosses: Feedback in team supervision. Journal of Further and Higher Education 39(3):320-335.

Guerin C, Bastalich W, Green I (2011). Big love: Managing a team of research supervisors. In: Kumar, V. \& Lee, A. (eds), Connecting the Local, Regional and International in Doctoral Education. Serdang: Universiti Putra Malaysia Press.

Hammond J, Ryland K, Tennant M, Boud DJ (2010). Building Research Supervision and Training Across Australian Universities. Canberra: Australian Learning and Teaching Council.

Hawkins P, Shohet R (2012). Supervision in the Helping Professions. 4th ed. Milton Keynes: Open University Press.

Hutchings M (2017). Improving Doctoral Support through Group Supervision: Analyzing Face-to-Face and Technology-Mediated Strategies for Nurturing and Sustaining Scholarship." Studies in Higher Education 42(3):533-550.

IRIC (2017). Activity report. Available at: https://www.iric.ca/en/press/activity-reports/2016-2017

Jeronimus (2014). Mutual Reinforcement Between Neuroticism and Life Experiences: A Five-Wave, 16-Year Study to Test Reciprocal Causation. Journal of Personality and Social Psychology 107(4):751764.

Katunguka-Rwakkishaya E (2007). Student-Supervisor Expectations in the Doctoral Supervision Process and Management of Doctoral Supervision: A working paper at a training of supervisors at Collin Hotel, Mukono, Kampala, Uganda

Kiley M (2011). Developments in Research Supervisor Training: Causes and Responses. Studies in Higher Education 36(5):585-599.

Kothari CR (2006). Research methodology: methods \& techniques. (2nd ed.). New Delhi: New Age International (P) Limited Publishers.

Laceulle E (2015). Why Not Everyone Gets Their Fair Share of Stress: Adolescent's Perceived Relationship Affection Mediates Associations Between Temperament and Subsequent Stressful Social Events. European Journal of Personality 29(2):125-137.

Lahenius K, Ikãvalko H (2012). Joint supervision practices in doctoral education - A student experience. Journal of Further and Higher Education 38(3):427-446.

Lee A (2008). How are Doctoral Students Supervised? Concepts of Doctoral Research Supervision. Studies in Higher Education 33(3):267-281.

Lee A (2012). Successful Research Supervision. Abingdon: Routledge.

Lee A, Murray R (2015). Supervising Writing: Helping Postgraduate Students Develop as Researchers. Innovations in Education and Teaching International 52(5):558-570.

Lizzio A, Stokes L, Wilson K (2005). Approaches to learning in professional supervision: Supervisee perceptions of processes and outcome. Studies in Continuing Education 27(3):239-256.

Malunda P, Ssentamu PN, Atwebembeire J (2021). Internal Quality Assurance Practices and Andragogy in Higher Education Institutions: Implications on $\mathrm{PhD}$ Training in Uganda. African Journal of Governance and Development 10(1):215-231.

Manathunga C (2011). Team' Supervision: New Positioning in Doctoral Education Pedagogies. In A. Lee and S. Danby (eds), Reshaping Doctoral Education: Changing Programs and Pedagogies 42-55.

Manathunga $C$ (2012). Supervisors watching supervisors: The deconstructive possibilities and tensions of team supervision. Australian Universities' Review 54(1):29-37.

Manathunga C (2014). Intercultural Postgraduate Supervision. Reimagining Time, Place and Knowledge. 1st ed. Abingdon: Routledge.
Massyn $L$ (2018). Engaging doctoral students to stay on track: A parttime doctoral student's perspective. 13th Quality in Postgraduate Research Conference, Adelaide, Australia pp. 17-19.

McAlpine L (2013). Doctoral Supervision: Not an Individual but a Collective Institutional Responsibility. Journal for the Study of Education and Development 36(3):259-280.

McCallin A, Nayar S (2012). Postgraduate supervision: A critical review of current practice. Teaching in Higher Education 17:63-74.

McCulloch A, Cassandra L (2016). Does Research Degree Supervisor Training work? The Impact of a Professional Development Induction Workshop on Supervision Practice." Higher Education Research and Development 35(5):968-982.

McCulloch A, Kumar V, van Schalkwyk S, Wisker G (2016). Excellence in doctoral supervision: An examination of authoritative sources across four countries in search of performance higher than competence. Quality in Higher Education 22(1):64-77.

Orellana ML (2016). Improving doctoral success by matching $\mathrm{PhD}$ students with supervisors. International Journal of Doctoral Studies 11:87-103.

Robertson MJ (2017a). Team modes and power: supervision of doctoral students. Higher Education Research and Development 36(2):358371.

Robertson MJ (2017b). Trust: the power that binds in team supervision of doctoral students. Higher Education Research and Development pp. 1-13.

Savva M, Nygaard LP (2021). Becoming a Scholar: Cross-cultural reflections on identity and agency in an education doctorate. UCL Press, OPEN ACCESS, https://www.jstor.org/stable/j.ctv17ppc4v

Spooner-Lane RS, Henderson DJ, Price RA, Hill G (2007). Practice to theory: Co-supervision stories. International Journal of Research Supervision 1(1):39-51.

Taylor S (2017). The Research Supervisor's Bibliography. Lichfield: UK Council for Graduate Education.

Turner G (2015). Learning to Supervise: Four Journeys. Innovations in Education and Teaching International 52(1):86-98.

Van Rooij E, Fokkens-Bruinsma M, Jansen E (2019). Factors that influence PhD candidates' success: the importance of PhD project characteristics, Studies in Continuing Education, DOI: $10.1080 / 0158037 X .2019 .1652158 T o$ link to this article: https://doi.org/10.1080/0158037X.2019.1652158

Wadesango N, Machingambi S (2011). Post graduate students' experiences with research supervisors. Journal of Sociology and Social Anthropology 2(1):31-37.

Watts J (2010). Team supervision of the doctorate: Managing roles, relationships and contradictions. Teaching in Higher Education 15(3):325-329.

Wisker G, Robinson G (2013). Doctoral 'orphans': Nurturing and supporting the success of postgraduates who have lost their supervisors. Higher Education Research and Development 32(2):300-313.

Zhao C, Golde CM, McCormick AC (2007). More than a signature: How advisor choice and advisor behaviour affect doctoral student satisfaction. Journal of Further and Higher Education 31(3):263-281. 